\title{
Blood donation among university students: Practices, motivations, and barriers in Saudi Arabia
}

\author{
Mohamed Salih Mahfouz, Majed Ryani, Nawar Ahmed Saleh Hamzi ${ }^{1}$, Dhaifallah Abdullah Zaeri ${ }^{1}$, \\ Abdullah Abdulrahman Dahdoh ${ }^{1}$, Abdulaziz Jaber Almalki ${ }^{1}$, Jubran Ahmed Ali Hakami ${ }^{1}$, Abkr Abdu Ahmed Aqeeli ${ }^{1}$, \\ Ibrahim Hussien Tawashi ${ }^{3}$ \\ Department of Family and Community Medicine, ${ }^{1}$ Faculty of Medicine, Jazan University, Jazan, Kingdom of Saudi Arabia
}

\begin{tabular}{|c|}
\hline Access this article online \\
\hline Website: www.avicennajmed.com \\
\hline DOI: 10.4103/ajm.ajm_113_20 \\
\hline Quick Response Code: \\
\hline
\end{tabular}

\begin{abstract}
Context: Blood transfusion is an essential medical procedure conducted with various purposes to provide patients with blood needed. The procedure saves patients' lives, as blood cannot be manufactured artificially and can only be obtained from human blood sources. Aims: To assess the awareness of, perceptions of, motivations regarding, and barriers to blood donation among a sample of Jazan University students in the Kingdom of Saudi Arabia (KSA). Settings and Design: An observational cross-sectional study was conducted among the undergraduate students of Jazan University. Materials and Methods: Stratified random sampling was used to collect information from 440 students, and a predesigned, structured questionnaire was used to collect data on the study variables. Statistical Analysis: Involved descriptive statistics and inferential statistics. SPSS was used for data analysis. Results: The prevalence of blood donation was $29.0 \%$ (95\% Cl, 25.0-33.3), significantly higher for males at $44.3 \%(95 \% \mathrm{Cl}, 38.3-50.4)$ than for females at $10.5 \%(95 \% \mathrm{Cl}, 7.3-16.0 ; P<0.001)$, and with odds ratio $(\mathrm{OR})=6.8 ;[95 \%$ $\mathrm{Cl}, 4.1-11.2]$ than females. Students' level of knowledge regarding blood donation was low. The main barriers to blood donation were identified as being unqualified for blood donation $(57.5 \%)$ and risk of contracting infectious disease $(48.7 \%)$ and the desire to donate in the future to a close friend (38.6\%). The main motivations for donating blood were identified as religious reasons $(77.5 \%)$, altruism $(77.5 \%)$, and to serve the homeland and meet the call of need $(77.5 \%)$. Conclusions: The prevalence of blood donation was found to be low, and students' knowledge regarding blood donation appeared to be lacking. The development of awareness programs among the university's students will address students' misconceptions about blood donation and encourage them to join donation campaigns.
\end{abstract}

Key Messages: Students' knowledge regarding blood donation appeared to be lacking. The prevalence of blood donation was also not satisfactory. Being unqualified for blood donation and fear and misconceptions regarding blood donation were observed to be the main causes of non-donation. The development of awareness programs among the university's students will encourage them to join donation campaigns.

Key words: Blood, donation, knowledge, motivations and barriers

\section{INTRODUCTION}

Blood donation is crucial in saving lives, as blood cannot be manufactured artificially and can thus be obtained only from human blood sources. ${ }^{[1]}$ Many surgical operations, medical

Address for correspondence: Dr. Mohamed Salih Mahfouz, Department of Family and Community Medicine,

Faculty of Medicine, Jazan, Saudi Arabia.

E-mail:mm.mahfouz@gmail.com
This is an open access journal, and articles are distributed under the terms of the Creative Commons Attribution-NonCommercial-ShareAlike 4.0 License, which allows others to remix, tweak, and build upon the work non-commercially, as long as appropriate credit is given and the new creations are licensed under the identical terms.

For reprints contact: reprints@medknow.com

How to cite this article: Mahfouz MS, Ryani M, Saleh Hamzi NA, Zaeri DA, Dahdoh AA, Almalki AJ, et al. Blood donation among university students: practices, motivations and barriers, Saudi Arabia. Avicenna J Med 2021;11:70-6. 
disorders, and potentially life-threatening conditions require blood transfusions as part of their basic management. Consequently, blood donation has become an essential process that every health care department should consider. ${ }^{[2]}$

According to the World Health Organization (WHO) and the International Federation of Red Cross and Red Crescent Societies, blood donors are usually volunteer donors, replacement donors, and paid donors. ${ }^{[1]}$ The WHO further recommends that countries should build their own systems, structures, and processes to effectively manage all aspects of blood donation to maintain the availability of blood whenever needed. ${ }^{[2]}$

Attitudes toward blood donation differ greatly between donors and nondonors. Altruism is one of the most significant and most commonly reported motivations for blood donation. ${ }^{[3]}$ Additionally, religious norms are an important motivating factor, especially in Middle Eastern countries. Similarly, national duty, family needs, and encouragement via social media are associated with the personal decision to donate. ${ }^{[4-6]}$

Conversely, the most commonly reported negative attitude toward blood donation that acts as a barrier to donating is fear. Potential donors also hold several misconceptions that need to be corrected, including beliefs about physical weakness, gender, age limitations, high risk of infections, and blood being sold to patients, which act as barriers to donation. ${ }^{[4]}$

Many studies have examined blood donation and transfusion among the Saudi population, and they have revealed valuable data about perceptions about and the prevalence of blood donation. ${ }^{[4-11]}$ A study conducted among the King Abdulaziz Medical City population aimed to measure respondents' knowledge of, attitudes toward, and motivations for donating blood. Almost $45.8 \%$ of respondents claimed that they had a history of donating blood. Reasons highlighted for not donating blood were blood donation not crossing respondents' minds (52.4\%), having no time for donation (45\%), and difficulty reaching blood donation centers (41.3\%). Motivating factors for donating blood included having the day off $(81.4 \%)$ and the availability of mobile blood donation units in public areas $(79.1 \%){ }^{[4]}$

Baig et al. ${ }^{[9]}$ conducted a study among university students in Saudi Arabia to assess respondents' knowledge about, misconceptions of, and motivations for donating blood. The study revealed that only $19.2 \%$ of respondents were donors, and the motivations for donation were to help family or friends (30\%), to save lives (28\%), for religious reasons
(20\%), and due to altruism (12\%). The same study showed that the most prevalent misconception was that donors could contract infections such as HIV and hepatitis B and $\mathrm{C}(26 \%) \cdot{ }^{[9]}$ In a recent community study conducted among 717 Saudi volunteers in Hail City, Saudi Arabia, the authors concluded that the concept of blood donation is still poorly understood in Saudi Arabia. ${ }^{[10]}$ Although many studies have been conducted in different parts of Saudi Arabia, ${ }^{[4-11]}$ no previous studies have been conducted in the Jazan region. Therefore, this study aims to assess the awareness and perceptions of, knowledge and misconceptions about, and motivations for blood donation, as well as reasons for not donating blood, among a sample of Jazan University students in the Kingdom of Saudi Arabia (KSA).

\section{Subjects and Methods}

\section{Study design, setting, and population}

An observational cross-sectional study was conducted among the undergraduate students of Jazan University. The University of Jazan, the principal educational institution in the region, opened in 2006 and now accommodates 23 colleges, with more than 2500 staff members and about 56,000 students. The university campus has a site area of $9 \mathrm{~km}^{2}$ on the Red Sea coast north of the city of Jazan. The study targeted undergraduate students enrolled for the 2017/2018 academic year between the ages of 18 and 25 years.

\section{Sampling procedures}

The sample size calculated was 480 based on the statistical formula used for cross-sectional study designs. The following parameters were used for the sample size calculation: prevalence of blood donation $=50 \%, 95 \%$ confidence interval (CI), error not more than $5 \%$, and a nonresponse rate of $20 \%$. A stratified random sampling technique was used to select study participants. We divided the university colleges into two groups, health-related colleges and other colleges (nonhealth colleges). From the first group, we randomly selected the college of Applied Medical Sciences and College of Dentistry, while from the second group, we selected the College of Sciences, College of Business Administration, College of Sharia and Law, and College of Arts and Humanities. In the last stage, systematic random sampling was used to proportionally select participants from each selected college.

\section{Data collection}

Data were collected for the study using a predesigned structured questionnaire whose design was based on WHO guidelines and the relevant literature. ${ }^{[5-10]}$ The selfadministered questionnaire was distributed by the study 
team. The study team first visited the target colleges, identified the study participants, stated the study objectives, and distributed the questionnaires. The study questionnaire had two sections. The first section consisted of questions regarding age, gender, standard of living, place of residence, and grade point average. The second section assessed students' awareness and perceptions of blood donation and related aspects.

\section{Data analysis}

The data were analyzed using SPSS version 20.0. Statistical analysis techniques involved descriptive and inferential statistics. Simple tabulation, frequencies, and percentages were used to present the data, and the chi-squared test was performed to determine associations. Questions on students' knowledge about blood donation were added into one score and then classified into three categories: low $(<40)$, medium (40-70), and high (70+). A $P$-value of $<0.05$ was used as the cut-off level for statistical significance.

\section{Ethical considerations}

The study was conducted in accordance with Saudi Arabian ethical guidelines. Ethical clearance was obtained from the Jazan University ethical committee. Before participation, students were informed that the information collected would be kept anonymous and that participation in the survey was absolutely voluntary. The purpose of the study was clarified, and all study participants signed study consent forms.

\section{Results}

A total of 468 students participated in this study (response rate $97.5 \% ; 468$ of 480 ). The gender distribution shows that 210 (44.9\%) were female, while 258 (55.1\%) were male. One hundred eighty-eight (41.8\%) were in the age group $22-23$ years, followed by $127(28.3 \%)$ in the age group 20-21 years. Most participants (390; 85\%) were single, while only $59(12.9 \%)$ were married. A total of $287(65.5 \%)$ had low economic status, 102 (23.3\%) moderate, and 49 (11.2\%) high economic status, as shown in Table 1.

Study participants' knowledge scores regarding blood donation are presented in Table 2. Most students (254; 51.6\%) had a low level of knowledge about blood donation, while 240 (44.4\%) and $14(3 \%)$ had medium and high knowledge scores, respectively. The differences in knowledge scores between age groups show no statistical significance $(P=0.6802)$. Male students showed higher knowledge scores than female students, with statistical a significance of $P=0.0014$.

The prevalence of blood donation was $29.0 \%$ (95\% CI, $25.0-33.3$ ); it was significantly higher for males at $44.3 \%$
(95\% CI, 38.3-50.4) than for females at 10.5\% (95\% CI, $7.3-16.0 ; P<0.001)$. Male respondents were more likely to be blood donors $[\mathrm{OR}=6.8$; 95\% CI, 4.1-11.2] than female respondents. College type had no significant influence on the prevalence of blood donation. Donors from the healthrelated colleges accounted for $28.5 \%$ (38) of the students, almost the same as the percentage for the other colleges (nonhealth colleges) (approximately 28\%). A significant positive statistical association was observed between blood donation and knowledge score $(P<0.0001)$. Comparing this association between age groups, a significant statistical association was observed $(P=0.000325)$. These results are displayed in Table 3.

Table 4 presents students' attitudes toward blood donation. Most study participants $(391 ; 84.1 \%)$ agreed that they would accept blood if they needed it, while 18 (3.7\%) disagreed. According to 371 (79\%), they needed more awareness of and guidance about the importance of blood donation; 57 (12.2\%) remained neutral, and 40 (8.4\%) did not need more information.

As shown in Figure 1, participants' most common motives to donate were religious reasons and altruism and to serve their homeland and meet the call of need. The least common motivation was to receive a reward. The most important barriers identified were lack of fitness to donate blood and the fear of catching diseases, while the least frequently mentioned was the lack of a special reward [Table 5].

\begin{tabular}{|c|c|c|}
\hline Percent & Frequency & Variables \\
\hline \multicolumn{3}{|l|}{ Gender } \\
\hline 55.1 & 258 & Male \\
\hline 44.9 & 210 & Female \\
\hline \multicolumn{3}{|c|}{ Age groups } \\
\hline 14.6 & 66 & $18-19$ \\
\hline 28.3 & 127 & $20-21$ \\
\hline 41.8 & 188 & $22-23$ \\
\hline 15.3 & 69 & $24+$ \\
\hline \multicolumn{3}{|l|}{ College } \\
\hline 29.5 & 135 & Health-related college \\
\hline 70.5 & 322 & Other colleges \\
\hline \multicolumn{3}{|l|}{ Residence } \\
\hline 39.4 & $|8|$ & Urban \\
\hline 60.6 & 278 & Rural \\
\hline \multicolumn{3}{|c|}{ Marital status } \\
\hline 12.9 & 59 & Married \\
\hline 2.2 & 10 & Divorced \\
\hline 85 & 390 & Single \\
\hline \multicolumn{3}{|c|}{ Economic status } \\
\hline 65.5 & 287 & Low \\
\hline 23.3 & 102 & Moderate \\
\hline 11.2 & 49 & High \\
\hline
\end{tabular}




\begin{tabular}{|c|c|c|c|c|}
\hline \multirow[t]{2}{*}{ Variable } & \multicolumn{3}{|c|}{ Knowledge score category, N (\%) } & \multirow[t]{2}{*}{$P$-value } \\
\hline & Low & Moderate & High & \\
\hline \multicolumn{5}{|l|}{ Age (years) } \\
\hline $18-19$ & $4 I(62 . I)$ & $23(34.8)$ & $2(3.0)$ & 0.6802 \\
\hline $20-21$ & $69(54.3)$ & $94(42.5)$ & $4(3.1)$ & \\
\hline $22-23$ & $92(48.9)$ & 91 (48.4) & $5(2.7)$ & \\
\hline $24+$ & $34(49.3)$ & $32(46.4)$ & $3(4.3)$ & \\
\hline \multicolumn{5}{|l|}{ Gender } \\
\hline Male & $116(45.0)$ & $129(50.0)$ & $13(5.0)$ & 0.0014 \\
\hline Female & $129(61.1)$ & $80(38.3)$ & $\mathrm{I}(0.5)$ & \\
\hline \multicolumn{5}{|l|}{ Levels } \\
\hline Ist & $63(67.0)$ & $28(29.8)$ & $3(3.2)$ & 0.0006 \\
\hline 2nd & $28(62.2)$ & $17(37.8)$ & $0(0)$ & \\
\hline $3 r d$ & $91(46.9)$ & $98(50.5)$ & $5(2.6)$ & \\
\hline 4th and 5th & $49(48.0)$ & $49(48.0)$ & $4(3.9)$ & \\
\hline \multicolumn{5}{|l|}{ Colleges } \\
\hline Health related colleges & $56(4 I .5)$ & $73(54.1)$ & $6(4.4)$ & 0.0021 \\
\hline Non-health colleges & $185(57.5)$ & $130(40.4)$ & $7(2.2)$ & \\
\hline Overall & $246(52.6)$ & $240(44.4)$ & $14(3)$ & \\
\hline
\end{tabular}

\begin{tabular}{|c|c|c|c|c|c|}
\hline Characteristic & Number donated/total & Prevalence & $95 \% \mathrm{Cl}$ & $P$-value & COR $(95 \% \mathrm{CI})$ \\
\hline \multicolumn{6}{|l|}{ Age group (years) } \\
\hline $18-19$ & $(9 / 66)$ & 13.6 & $7.4-23.9$ & 0.0032 & I \\
\hline $20-21$ & $(34 / 126)$ & 26.9 & $20.0-35.3$ & & $6.0(2.5-13.9)^{*}$ \\
\hline $22-23$ & $(51 / 187)$ & 27.3 & $21.3-34.0$ & & $2.6(1.4-4.7)^{*}$ \\
\hline $24+$ & $(34 / 68)$ & 50.0 & $38.4-61.6$ & & $2.5(1.4-4.4)^{*}$ \\
\hline \multicolumn{6}{|l|}{ Colleges } \\
\hline Health-related colleges & $(38 / 133)$ & 28.5 & $21.6-36.8$ & 0.2226 & $1.02(0.67-1.6)$ \\
\hline Non-health colleges & $(90 / 321)$ & 28.0 & $23.4-33.2$ & & I \\
\hline \multicolumn{6}{|l|}{ Gender } \\
\hline Male & $(113 / 255)$ & 44.3 & $38.3-50.4$ & $<0.0001$ & $6.8(4 .|-| I .2)$ \\
\hline Female & $(22 / 210)$ & 10.5 & $7.3-16.0$ & & $\mathrm{I}$ \\
\hline \multicolumn{6}{|l|}{ Knowledge score } \\
\hline Low & $(53 / 245)$ & 21.6 & $16.9-27.2$ & $<0.0001$ & I \\
\hline Moderate & $(74 / 206)$ & 35.9 & $29.7-42.7$ & & $4.8(1.6-14.5)^{*}$ \\
\hline High & $(8 / 14)$ & 57.1 & $32.3-78.7$ & & $2.4(0.8-7.1)$ \\
\hline Overall prevalence & $(135 / 465)$ & 29.0 & $25.0-33.3$ & & \\
\hline
\end{tabular}

\begin{tabular}{|c|c|c|c|c|c|c|}
\hline Statement & SA, $N(\%)$ & $A, N(\%)$ & $\mathbf{N}, \mathbf{N}(\%)$ & DA, $N(\%)$ & SD, $N(\%)$ & Mean \\
\hline I will accept blood if I need it. & $233(50.1)$ & $158(34)$ & $56(12.0)$ & $12(2.6)$ & $6(1.3)$ & 1.70 \\
\hline I will accept blood from friends and relatives. & $84(17.9)$ & $92(19.7)$ & $167(35.7)$ & $87(18.6)$ & $38(8.1)$ & 2.79 \\
\hline I approve of blood donation and am motivated to do it. & $253(54.2)$ & $142(30.4)$ & $61(13.1)$ & $10(2.1)$ & I (0.2) & 1.63 \\
\hline I will donate blood if I receive notification of the need for blood. & 209 (44.7) & $188(40.2)$ & $60(12.8)$ & $8(1.7)$ & $3(0.6)$ & 1.73 \\
\hline I will donate blood if I receive a financial reward. & $97(20.7)$ & $60(12.8)$ & III (23.7) & $107(22.9)$ & $93(19.9)$ & 3.08 \\
\hline $\begin{array}{l}\text { Awareness and guidance for blood donation in our community } \\
\text { is sufficient. }\end{array}$ & $70(15)$ & $129(27.7)$ & $134(28.6)$ & $103(22)$ & $32(6.8)$ & 2.78 \\
\hline $\begin{array}{l}\text { I need more awareness and guidance about the importance of } \\
\text { blood donation. }\end{array}$ & $157(33.5)$ & $214(45.7)$ & $57(12.2)$ & $29(6.2)$ & II (2.4) & 1.98 \\
\hline
\end{tabular}

\section{Discussion}

The present study was conducted at Jazan University to understand the various factors contributing to people's beliefs, attitudes, and level of knowledge about blood donation and transfusion. To the best of the authors' knowledge, this is the first survey to be conducted among Jazan University students to explore this important issue. Blood donation is an important procedure that frequently needs to be conducted in health care settings. In Jazan especially, blood transfusions are common because of the high prevalence of inherited blood diseases that require transfusions in their management, in addition to other health issues that require transfusions.

Participants' knowledge regarding blood donation was found to be low, as they were not aware of the principles of blood donation. These results agree with national studies ${ }^{[7-10]}$ 


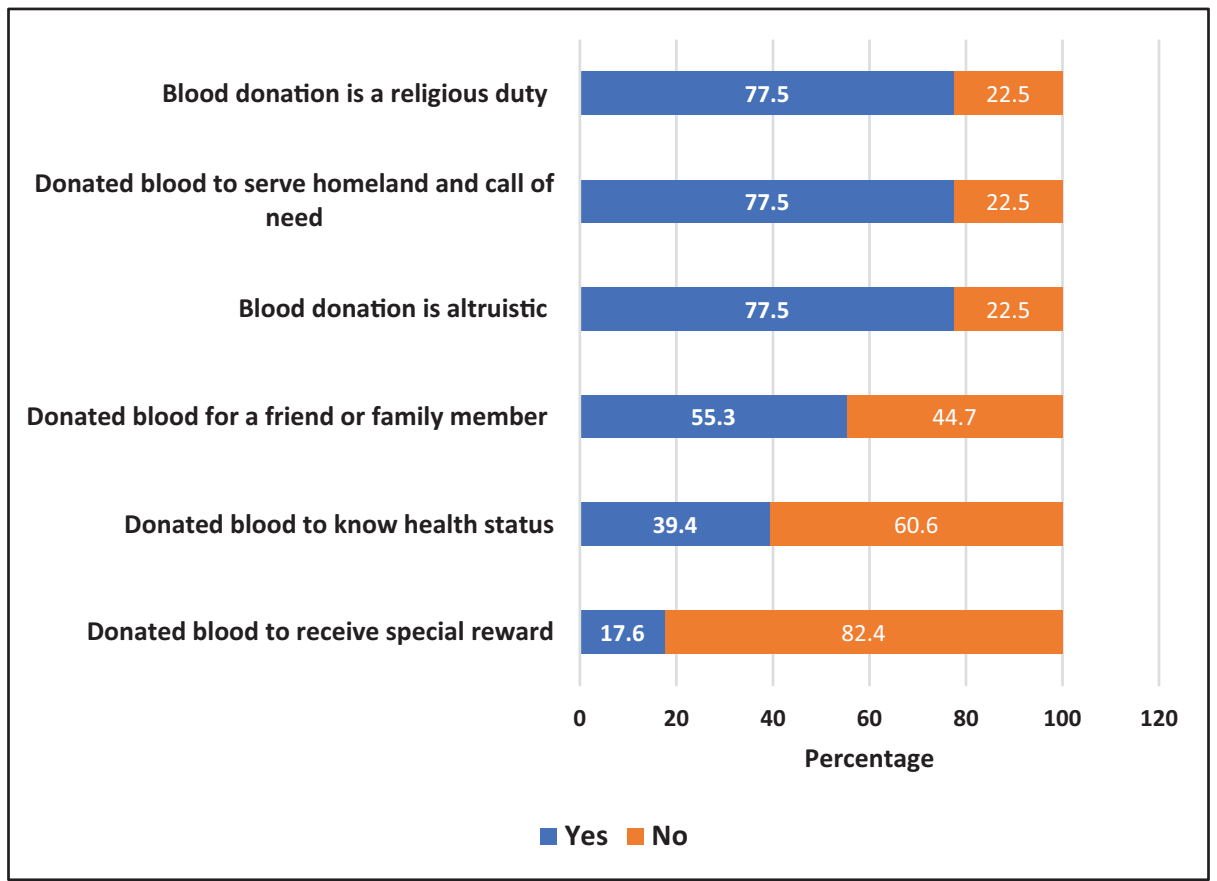

Figure 1: Motives behind blood donation in blood donors

\begin{tabular}{lc}
\hline Table 5: Barriers related to blood donation among nondonors & \\
\hline Statement & Yes, $\mathbf{N}(\%)$ \\
\hline Unqualified for blood donation & $260(57.5)$ \\
Fear of catching diseases & $220(48.7)$ \\
Desire to donate in the future to a close friend & $1 \%)$ \\
Belief that the donated blood will be sold to the patient & $174(38.6)$ \\
Fear of needle pain & $152(37.7)$ \\
Fear of knowing health status & $154(34.2)$ \\
Pain during the withdrawal of the blood sample & $147(32.7)$ \\
Lack of special reward & $133(29.4)$ \\
\hline
\end{tabular}

and international studies conducted in Jordan ${ }^{[12]}$ and Kuwait. ${ }^{[13]}$ Alsalmi et al. ${ }^{[11]}$ in their study among health professions students in Saudi Arabia, concluded that the level of awareness was sufficient at $60 \%$ of study participants.

Our study results reveal that among 468 respondents, $71 \%$ were nondonors, while $29 \%$ were donors. In comparison, a study conducted at King Abdulaziz University's Rabigh campus found that $80.89 \%$ of respondents were nondonors and $19.02 \%$ were donors. ${ }^{[6]}$ The study revealed a high prevalence of donors among students attending the health colleges $(29.1 \%)$. Mustafa et al. ${ }^{[14]}$ found a slightly higher prevalence (14\%). Comparing our estimate with international studies on university students, the prevalence in our study is higher than that reported in Iraq $(14 \%)^{[15]}$ and Nigeria $(15 \%){ }^{[16]}$ but lower than that reported in Iran $(24.6 \%),{ }^{[17]}$ Ethiopia (23.4\%), ${ }^{[18]}$ and Greece (24\%). ${ }^{[19]}$ Furthermore, it is much lower than that reported among university students in the United States $(56 \%)^{[20]}$ and Nepal $(43 \%){ }^{[21]}$
A significant statistical difference in donor status was observed between genders, with significantly fewer female donors compared with male donors, a phenomenon also found elsewhere in the world. ${ }^{[13,15,22]}$ Our findings align with previous studies conducted in the KSA, ${ }^{[4,5,7,23]}$ which reported that men have a significantly higher tendency to donate blood than women and that women are underrepresented among blood donors. Generally, women experience approximately $70 \%$ more deferrals from donation than men as a result of anemia, other health conditions, and clinical reactions. ${ }^{[24-26]}$

Our study revealed that the most important motivations for blood donation were religion and altruism. In the Middle East, Islamic regulations are a major motivating factor for blood donation, as $77.5 \%$ of the donors who participated in this research believed that blood donation is a religious duty. This finding aligns with most studies conducted in the KSA. ${ }^{[4-7,9]}$ Other motivations reported were serving the homeland and meeting the call of need, while the least common was to receive a reward, which also aligns with most literature. ${ }^{[27-29]}$ 
Barriers to blood donation include being unqualified for blood donation (57.5\%) and fear of catching diseases (48.7\%). Fear of not being fit to donate has been reported frequently in studies from China $(63.2 \%)^{[30]}$ and Moldova $(60.0 \%){ }^{[31]}$ Fear of contracting diseases is well known and has been documented in many studies. ${ }^{[32-34]}$

Although this study provides contemporary evidence on the prevalence of, awareness of, motivations for, and barriers to blood donation in the Jazan region for the first time, it has some limitations. First, the study is based on a cross-sectional design, so the temporal association between awareness of and attitude toward blood donation and the prevalence of blood donation cannot be properly established. Second, information on the prevalence of blood donation was based only on study participants' reporting (or not reporting) their hospital records. Thus, participants' accuracy of reporting may affect the accuracy of the information.

Students' knowledge regarding blood donation appeared to be lacking. The prevalence of blood donation is also low. Being unqualified for blood donation and fear and misconceptions regarding blood donation were observed to be the main causes of non-donation. The development of awareness programs among the university's students will encourage them to join donation campaigns.

\section{Acknowledgements}

We would like to acknowledge all students who participated in this survey and the staff of the Department of Family and Community Medicine for their cooperation and support.

\section{Financial support and sponsorship}

Nil.

\section{Conflicts of interest}

There are no conflicts of interest.

\section{References}

1. World Health Organization (WHO). Towards $100 \%$ Voluntary Blood Donation, A Global Framework for Action 2017. Available from: http:// www.who.int/bloodsafety/publications/9789241599696/en/. cited 2020 [Last accessed on 2020 Nov 20].

2. WHO. Fact Sheet No. 279. Blood Safety and Availability. Available from: http://www.who.int/mediacentre/factsheets/fs279/en/index.html. cited 2020 [Last accessed on 2020 Oct 20].

3. Bednall TC, Bove LL, Cheetham A, Murray AL. A systematic review and meta-analysis of antecedents of blood donation behavior and intentions. Soc Sci Med 2013;96:86-94.

4. Alfouzan N. Knowledge, attitudes, and motivations towards blood donation among King Abdulaziz Medical City population. Int J Family Med 2014;2014:539670.
5. Abolfotouh MA, Al-Assiri MH, Al-Omani M, Al Johar A, Al Hakbani A, Alaskar AS. Public awareness of blood donation in central Saudi Arabia. Int J Gen Med 2014;7:401-10.

6. Abdel Gader AG, Osman AM, Al Gahtani FH, Farghali MN, Ramadan AH, Al-Momen AK. Attitude to blood donation in Saudi Arabia. Asian J Transfus Sci 2011;5:121-6.

7. Al-Drees AM. Attitude, belief and knowledge about blood donation and transfusion in Saudi population. Pak J Med Sci 2008;24:74.

8. Alam M, Masalmeh BD. Knowledge, attitudes and practices regarding blood donation among the Saudi population. Saudi Med J 2004;25:31821.

9. Baig M, Habib H, Haji AH, Alsharief FT, Noor AM, Makki RG. Knowledge, misconceptions and motivations towards blood donation among university students in KSA. Pak J Med Sci 2013;29:1295-9.

10. Alharbi SH, Alateeq FA, Ahmed IB, Alsogair AAA, Al-Rashdi YDA, Aldugieman TZ, et al. Assessment of levels of awareness towards blood donation in saudi arabia. AIMS Public Health 2018;5:324-37.

11. Alsalmi MA, Almalki HM, Alghamdi AA, Aljasir BA. Knowledge, attitude and practice of blood donation among health professions students in Saudi Arabia: A cross-sectional study. J Family Med Prim Care 2019;8:2322.

12. Batiha AM, AlBashtawy M. Knowledge of Philadelphia university students regarding blood donation. Transfus Med 2013;23:195-8.

13. Al-Haqqan T, Husain A, Al-Kandari N, Al-Rashidi L, Al-Daihani N, Mitra AK. A cross-sectional study of knowledge, attitude, practice, and barriers regarding blood donation among general population in Kuwait. Int J Comm Fam Med 2016;1:ICJFM-120.

14. Mustafa MM, Abdelfattah EN, Al Rukban MO. Attitude towards blood donation among university students. Int J Sci Basic Appl Res 2015;19:82-91.

15. Al-Asadi JN, Al-Yassen AQ. Knowledge, attitude and practice of blood donation among university students in Basrah, Iraq: A comparison between medical and non-medical students. Asian J Med Sci 2018;9:62-7.

16. Salaudeen AG, Odeh E. Knowledge and behavior towards voluntary blood donation among students of a tertiary institution in Nigeria. Niger J Clin Pract 2011;14:303-7.

17. Safizadeh H, Pourdamghan N, Mohamadi B. University student's awareness and attitude towards blood donation in Kerman City. Iran J Blood Cancer 2009;1:107-10.

18. Misganaw C, Tenkir M, Deresea A, Tesfaye M, Tessema TT, Taye H. The level and associated factors of knowledge, attitude and practice of blood donation among health science students of Addis Ababa health science students of Addis Ababa University. Int J Med Res Health Sci 2014;1:105-18.

19. Papagiannis D, Rachiotis G, Symvoulakis EK, Anyfantakis D, Douvlataniotis K, Zilidis C, et al. Blood donation knowledge and attitudes among undergraduate health science students: A crosssectional study. Transfus Apher Sci 2016;54:303-8.

20. Allerson J. Assessment of selected university students' knowledge of blood donation and the relationship with intent to donate blood. Master's thesis. Minnesota State University, Mankato; 2012.

21. Mamatya A, Prajapati R, Yadav R. Knowledge and practice of blood donation: A comparison between medical and nonmedical Nepalese students. Nep Med Coll J 2012;14:283-6.

22. Bani M, Strepparava M, Giussani B. Gender differences and frequency of whole blood donation in italian donors: Even though I want to, I cannot? Transfus Apher Sci 2014;50:81-6.

23. Al-Johar AW, Al-Saud A, Abalkhail Y, Jawdat T, Al-Khamees S, AlThunayan Faisal, et al. Why do-saudi women refrain donating their blood?-a study on the attitude, belief and motivation of Saudi female university students towards blood donation. Clin Lab 2016;62:771-9.

24. Bani M, Giussani B. Gender differences in giving blood: A review of the literature. Blood Transfus 2010;8:278-87. 
25. Newman BH, Newman DT, Ahmad R, Roth AJ. The effect of wholeblood donor adverse events on blood donor return rates. Transfusion 2006;46:1374-9.

26. Nilsson Sojka B, Sojka P. The blood-donation experience: Perceived physical, psychological and social impact of blood donation on the donor. Vox Sang 2003;84:120-8.

27. Mishra SK, Sachdev S, Marwaha N, Avasthi A. Study of knowledge and attitude among college-going students toward voluntary blood donation from North India. J Blood Med 2016;7:19-26.

28. Singh B, Pandey RM, D'Souza N. Knowledge, attitudes and sociodemographic factors differentiating blood donors from non-donors in an urban slum of Delhi. Indian J Commun Med 2002;27:118-21.

29. Goncalez TT, Sabino EC, Chen S, Salles NA, Chamone DAF, McFarland W, et al. Knowledge, attitudes and motivations among blood donors in São Paulo, Brazil. AIDS Behav 2008;12:S39-47.
30. Zaller N, Nelson KE, Ness P, Wen G, Bai X, Shan H. Knowledge, attitude and practice survey regarding blood donation in a northwestern Chinese city. Transfus Med 2005;15:277-86.

31. United States Agency for International Development (USAID). Blood Donation in Moldova: Knowledge, Attitudes, and Practice in the General Population: Survey Final Report. Washington, DC: USAID; 2007.

32. Jacobs B, Berege ZA. Attitudes and beliefs about blood donation among adults in Mwanza region, Tanzania. East Afr Med J 1995;72:345-8.

33. Agbovi KK, Kolou M, Fétéké L, Haudrechy D, North ML, Ségbéna AY. [Knowledge, attitudes and practices about blood donation. A sociological study among the population of lomé in Togo]. Transfus Clin Biol 2006;13:260-5.

34. Olaiya MA, Alakija W, Ajala A, Olatunji RO. Knowledge, attitudes, beliefs and motivations towards blood donations among blood donors in Lagos, Nigeria. Transfus Med 2004;14:13-7. 